\title{
Language, Space and Power: A Critical Look at Bilingual Education
}

Samina Hadi-Tabassum. Clevedon, UK: Multilingual Matters. 2006. Pp. v + 295.

Through the close analysis of and critical discussion surrounding a fifth-grade dual-immersion classroom, Hadi-Tabassum explores the often inequitable role of language in the classroom. In her critical ethnographic study entitled Language, Space and Power: A Critical Look at Bilingual Education, young learners of both Spanish and English are observed as they engage themselves in various classroom tasks and metalinguistic discussions. Based on the ethnographic observation, parallels are drawn between such concepts as identity, language, and power. As a result, Hadi-Tabassum is able to explore what she deems the third space, a space where awareness focuses upon a desire to overcome linguistic borders and boundaries. Through an emphasis upon discourse rather than language acquisition, the author shows how conflicts over language use and the mediation of these conflicts arise.

After establishing the setting of the study in chapter 1, Hadi-Tabassum devotes time to presenting and confirming the presence of language within a bilingual brain. She then goes on to present the space perimeters persisting within dual-immersion classrooms in chapter 2 . To begin, an investigation of the binary and dichotomous existence of language within a dual-immersion language classroom is conducted. In this way, the adherence to a belief system encompassing two separate and nonoverlapping languages as the perceived norm of a dual-immersion program readily emerges. In the classroom observed in this study, English and Spanish were separated temporally through the classroom schedule and spatially through the classroom design. By doing this, borders and boundaries between these two languages were constructed and the agency of the teacher and students were established. The role of power in relation to language comes to light through focusing upon the desk area in contrast to the rug area, the hypothetical third space of this fifth grade classroom. One way in which the role of power is perceived can be found in the student-dominated but sometimes teacher-controlled dialogue observed at the Spanish spelling bee competition. The author argues that because of the presence of the third space within the classroom, the dialogue allowing students to raise critical awareness and to question the role of their two languages was possible, thus acknowledging the marginalization of one discourse over another and the conflicts of power this presents.

In chapter 3, the author offers a close look at one particular class endeavor within this fifth-grade classroom. Upon receiving and accepting a school-wide invitation to create a class cheer, the dual-immersion class moves towards developing a cheer that will project their identity and which they, in turn, will be able to share with the school. To begin this project, the class divides itself into three smaller groups in order to create a cheer that is believed to represent the class. This student-initiated group division reflects a separation of gender, class, and ethnic identities. Thus, the cheers that are ultimately created by each subgroup are very different in concept, linguistic construction, and appearance. They also appear to mirror the divided identities and invoke the notions of aesthetics and the perceived role of cheerleading. Additionally, the development of culturally-specific cheers and the ultimately teacher-centered selection of the cheer to be performed by the entire group, multiple aspects of cultural legitimacy and cultural capital are applied that encompass the blurred boundaries between pedagogy and aesthetics as well as language and power. 
In the subsequent chapter, another close investigation of a particular classroom project invites analyses and critical questioning of not only the role of the two languages, but also ideologies surrounding race, class, and gender. Through delving into third space imaginings, a space between reality and fantasy, the students, the teacher, and the student-teacher in the dualimmersion classroom invite performance into their lives. They work together on the pages of a text, Juan Bobo, and put together a classroom play, Jack, Su Mama, Y El Burro. Both of these texts have tradition, folk culture, and primitiveness in common. In Juan Bobo, for instance, the poor, Afro-Hispanic protagonist, Juan, becomes representative of the social and economic imbalance of non-Western cultures. This lack of development and primitive otherness envisioned through race and class, in turn, becomes absorbed by young readers. Furthermore, the fictional text becomes real within the eyes of the dual-immersion students when they begin applying this identity to one of their classmates. In this way, the other becomes not a fantasy but a reality for the students. In Jack, Su Mama, Y El Burro, an Afro-Cuban folk play, strides towards mimicking the typical and stereotypical culture are attempted. The play, which mirrors the expectations of the culture itself, does not move towards raising questions about power, positioning, and postcolonial otherness, but rather reflects the accepted traditions of a people and a place. Student depictions that challenge roles of gender through, for example, the portrayals of male characters by female students and vice versa, move towards overcoming traditionally prescribed borders. Additionally, several of the student performers portray behaviors that potentially narrow the gap between fantasy and reality, past and present, through the improvisation of lines enhancing the Spanish text within the play.

The final chapter of Hadi-Tabassum's text focuses upon yet another notion of third space which is accomplished through the implementation of music. Music positions itself quite readily between language and thought and, because of this, evokes varying experiences and perceptions. For dual-immersion students, the inclusion of a Spanish music class allows for boundaries between the English- and Spanish-dominant students to become less prominent. It also invites fluidity among and between the students and their learning experiences. By devoting a distinct portion of instructional time to the integration and production of Spanish music, the unequal linguistic presence within this fifth grade classroom, the established border between the dominant English and less-dominant Spanish, becomes somewhat alleviated. Through mimicry, both groups of students in the dual-immersion classroom were able to position themselves in a third space of hybridity and dynamism. For the English-dominant students, a space between one's self and the other was established through the milieu of Spanish music. On the other hand, the Spanish-dominant students confronted and maintained an ethnic third space, which allowed them to explore the multiple cultural and social groups evident within the Spanish language sphere.

Overall, Hadi-Tabassum's book provides an interesting and critical look within the walls of a dual-immersion classroom. She provides an engaging exploration of the many angles and depths of bilingual education and gives the reader insights into the unequivocal spaces often created and maintained within a bilingual classroom environment. Unquestionably, this book is a fascinating linguistic exploration for those interested in ideas surrounding power, identity, gender, race, and class, as well as those investigating notions of critical questioning and awareness within the minds of language learners. 
Teachers College, Columbia University, Working Papers in TESOL \& Applied Linguistics, 2007, Vol. 7, No.1 Book Review

ANNE C. WEBER

Temple University 